\title{
Biological effects of melatonin on human adipose-derived mesenchymal stem cells
}

\author{
JUNE SEOK HEO ${ }^{1 *}$, SANGSHIN PYO $^{1 *}$, JA-YUN LIM $^{1 *}$, DAE WUI YOON ${ }^{2}$, BO YONG KIM $^{3}$, \\ JIN-HEE KIM ${ }^{4}$, GI JIN KIM ${ }^{5}$, SEUNG GWAN LEE ${ }^{3}$ and JINKWAN KIM ${ }^{2}$ \\ ${ }^{1}$ Department of Integrated Biomedical and Life Sciences, College of Health Science, Korea University, Seoul 02841; \\ ${ }^{2}$ Department of Biomedical Laboratory Science, College of Health Science, Jungwon University, Geosan, \\ Chungbuk 28024; ${ }^{3}$ Department of Health and Environmental Science, College of Health Science, Korea University, \\ Seoul 02841; ${ }^{4}$ Department of Biomedical Laboratory Science, College of Health Science, Cheongju University, \\ Cheongju, North Chungcheong 28497; ${ }^{5}$ Department of Biomedical Science, \\ CHA University, Seongnam, Gyeonggi 13488, Republic of Korea
}

Received June 21, 2019; Accepted September 11, 2019

DOI: $10.3892 /$ ijmm.2019.4356

\begin{abstract}
Mesenchymal stem cells (MSCs) are capable of differentiating into other cell types and exhibit immunomodulatory effects. MSCs are affected by several intrinsic and extrinsic signaling modulators, including growth factors, cytokines, extracellular matrix and hormones. Melatonin, produced by the pineal gland, is a hormone that regulates sleep cycles. Recent studies have shown that melatonin improves the therapeutic effects of stem cells. The present study aimed to investigate whether melatonin enhances the biological activities of human adipose-derived MSCs. The results demonstrated that treatment with melatonin promoted cell proliferation by inducing SRY-box transcription factor 2 gene expression and preventing replicative senescence. In addition, melatonin exerted anti-adipogenic effects on MSCs. PCR analysis revealed that the expression of the CCAAT enhancer binding protein a gene, a key transcription factor in adipogenesis, was decreased following melatonin treatment, resulting in reduced adipogenic differentiation in an in vitro
\end{abstract}

Correspondence to: Professor Jinkwan Kim, Department of Biomedical Laboratory Science, College of Health Science, Jungwon University, 50-1M1 802, 85 Munmu-ro, Geosan-eup, Geosan, Chungbuk 28024, Republic of Korea

E-mail: jkkim@jwu.ac.kr

Professor Seung Gwan Lee, Department of Health and Environmental Science, College of Health Science, Korea University, Anam Campus, 145 Anam-ro, Seongbuk-gu, Seoul 02841, Republic of Korea

E-mail: seunggwan@korea.ac.kr

*Contributed equally

Key words: cellular therapy, luzindole, melatonin, mesenchymal stem cells assay. The present study also examined the effect of melatonin on the immunomodulatory response using a co-culture system of human peripheral blood mononuclear cells and MSCs. Activated T cells were strongly inhibited following melatonin exposure compared with those in the control group. Finally, the favorable effects of melatonin on MSCs were confirmed using luzindole, a selective melatonin receptor antagonist. The proliferation-promoting, anti-inflammatory effects of melatonin suggested that melatonin-treated MSCs may be used for effective cell therapy.

\section{Introduction}

The biological activities of mesenchymal stem cells (MSCs), such as anti-inflammatory activities, render them a promising tool for cell-based regenerative medicine (1). Among adult stem cells, adipose-derived MSCs (AdMSCs) can be readily obtained in large quantities using a simple procedure, and rapidly expanded in vitro (2). AdMSCs, capable of differentiating into osteoblasts, adipocytes and chondrocytes via the activation of several key transcription factors, have been shown to be effective in the treatment of atrophy, fibrosis, retraction, and ulcers, as well as in wound healing. In addition, the immunomodulatory function of AdMSCs has been effective in treating hematological and immunological diseases $(2,3)$. Several studies to date have revealed the considerable potential of AdMSCs in regenerative medicine $(4,5)$.

Melatonin (N-acetyl-5-methoxytryptamine), mainly synthesized from tryptophan and produced by the pineal gland, is involved in diverse physiological activities, including sleep cycle regulation, cell proliferation control, and antioxidant and anti-inflammatory activities (6). In general, melatonin, which regulates physiological and endocrinological functions, is used for treating sleep disorders, such as insomnia (7). Recently, melatonin was reported to exhibit both proliferation-promoting and anti-inflammatory properties, not only by enhancing the self-renewing potential of stem cells, but also by reducing the expression of pro-inflammatory factors $(8,9)$. Several studies 
have demonstrated that the melatonin receptors type (MT) 1 and 2 can be detected in adipose tissue, and daily melatonin treatment inhibits adipose accumulation $(10,11)$. In addition, melatonin has been demonstrated to suppress the adipocyte differentiation of murine pre-adipocytes (12). In this regard, melatonin exhibits the potential to prevent obesity, as well as obesity-related metabolic diseases, although the mechanisms underlying melatonin-related reduction in adiposity via adipogenesis remain unknown (13).

Previous studies have shown that the MT1 and MT2 melatonin receptors are expressed in human MSCs (14). Melatonin is known to improve the functionality of MSCs via its cognate receptors (15). Melatonin pretreatment enhances the therapeutic potential of MSCs by maintaining their self-renewability during in vitro expansion (16). Melatonin also influences MSC survival in in vivo animal studies (17). Another study reported that melatonin prevented the replicative senescence of AdMSCs through a sirtuin 1-dependent pathway (18). Successful in vitro expansion of MSCs is an essential procedure for clinical application, because of cellular aging due to long-term passaging of cells. Nevertheless, studies regarding whether a small molecule such as melatonin can improve the proliferation, differentiation and immunomodulatory ability of AdMSCs are still lacking. Furthermore, the mechanisms underlying the biological effects of melatonin in AdMSCs have not been elucidated.

The maintenance of stemness in MSCs is regulated by a complex network, including intracellular and extracellular signaling (19). Diverse strategies have been applied to improve the expansion and stemness of MSCs by providing a favorable microenvironment $(20,21)$. The present study aimed to establish such a strategy, using the small molecule melatonin to improve AdMSC cell therapy. Such small cell-permeable molecules can provide robust and reproducible results, and affect signaling pathways (22). Additionally, the present study investigated whether melatonin treatment could improve the proliferative activity and anti-inflammatory effects of MSCs, and whether it could regulate the tri-lineage differentiation potential of MSCs compared with normal culture conditions. Furthermore, the melatonin effects on the proliferative and immunomodulatory properties of AdMSCs via the melatonin receptors were confirmed using the melatonin antagonist, luzindole.

\section{Materials and methods}

Isolation of AdMSCs. Adipose tissues were obtained from 3 different normal healthy donors (female; age, 42, 53 and 55 years, collected at CHA Hospital on September-December 2018) after providing written informed consent. This study was approved by the Institutional Review Board of CHA General Hospital, Seoul, Korea. AdMSCs were isolated using freshly prepared $0.1 \%$ collagenase type I solution (Invitrogen; Thermo Fisher Scientific, Inc.). After incubation at $37^{\circ} \mathrm{C}$ for $1 \mathrm{~h}$, an equal amount of growth medium [DMEM with $10 \%$ FBS and 1\% penicillin/streptomycin (all Thermo Fisher Scientific, Inc)] was added to the mixture to arrest enzyme activity. After centrifugation at 1,200 x $\mathrm{g}$ for $5 \mathrm{~min}$, the upper layer of the supernatant was removed, and the lower part of the mixture was filtered through a $70 \mu \mathrm{m}$ cell strainer. After centrifugation at 1,200 x g for $5 \mathrm{~min}$, the supernatant was removed and the pellet was resuspended with growth medium by pipetting. After centrifugation at $1,200 \mathrm{xg}$ or $5 \mathrm{~min}$, the supernatant was removed, and the cells were cultured in DMEM, supplemented with 10\% FBS and 1\% penicillin/streptomycin. The cells were cultured at $37^{\circ} \mathrm{C}$ under $5 \% \mathrm{CO}_{2}$, and the media were supplemented with $5 \mathrm{ng} / \mathrm{ml}$ basic fibroblast growth factor (Invitrogen; Thermo Fisher Scientific, Inc.) every 3 or 4 days. The cultivated cells exhibited the typical spindle shape of AdMSCs. The cells were positive for expression of the surface antigens CD73, CD90 and CD105 (data not shown). Cells were passaged with trypsin-EDTA (Invitrogen; Thermo Fisher Scientific, Inc.) when they reached 80-90\% confluence. The cultured AdMSCs were frozen until the cells were used at passages 5-10. Melatonin (Sigma-Aldrich; Merck $\mathrm{KGaA}$ ) and luzindole (Sigma-Aldrich; Merck KGaA) were dissolved in DMSO, and the cells were photographed after melatonin treatment under an inverted light phase-contrast microscope (IX-71; Olympus Corporation). Experiments were performed three times from three different donors for the present study.

Cell proliferation assay. AdMSCs were plated at a density of $1 \times 10^{3}$ cells/well in 96 -well plates to determine the proliferation rate of AdMSCs. Each well of the culture plate was treated with varying concentrations $(0.5-50 \mu \mathrm{M})$ of melatonin for 3 days, along with $5 \mu \mathrm{M}$ of luzindole. In all experiments, when melatonin was added to the well, it was marked as 'melatonin' or MT, and untreated control was labeled as 'control' or 'CON.' In addition, when luzindole was added along with melatonin to the cells, these were labeled as LU + MT. Proliferation activity was determined using the EZ-Cytox kit (DaeilLab Services) based on the WST reagent. The results were analyzed according to the manufacturer's instructions. Data were expressed as the mean \pm SD of three independent experiments.

Reverse transcription (RT-) PCR. Total RNA was extracted using a RiboEx solution (GeneAll Biotechnology Co., Ltd.). Standard reverse transcription was performed using a Maxime $^{\mathrm{TM}}$ RT Premix (Intron Biotechnology, Inc.). To amplify target genes, $25 \mathrm{ng}$ cDNA was used along with the PCR primers (Bioneer Corporation) using the conditions listed in Table I. The amplification program consisted of 24-35 cycles of the following conditions: $94^{\circ} \mathrm{C}$ for $30 \mathrm{sec}$; annealing at $62^{\circ} \mathrm{C}$ for $30 \mathrm{sec}$, and extension at $72^{\circ} \mathrm{C}$ for $30 \mathrm{sec}$, followed by a final amplification step for $10 \mathrm{~min}$ at $72^{\circ} \mathrm{C}$. The PCR products were visualized by agarose gel electrophoresis. GAPDH was used as an internal reference control. One representative example of three independent experiments is shown.

Quantitative PCR ( $q P C R)$. Total RNA was extracted using RiboEx reagent (GeneAll Biotechnology Co., Ltd.). Isolated RNA was reverse-transcribed into cDNA using a Maxime ${ }^{\mathrm{TM}}$ RT PreMix (Intron Biotechnology, Inc.), according to the manufacturer's protocol.qPCR was performed in 96-well plates using SYBR-Green I Master mix (Roche Applied Science) on a LightCycler 480 System (Roche Applied Science) using the following cycling conditions: $95^{\circ} \mathrm{C}$ for $5 \mathrm{~min}$, and 45 cycles of $95^{\circ} \mathrm{C}$ for $10 \mathrm{sec}, 60^{\circ} \mathrm{C}$ for $20 \mathrm{sec}$, and $72^{\circ} \mathrm{C}$ for $15 \mathrm{sec}$, followed 
Table I. Primer sequences.

\begin{tabular}{|c|c|c|}
\hline Gene symbol & Primer sequence $\left(5^{\prime}-3^{\prime}\right)$ & Annealing temperature $\left({ }^{\circ} \mathrm{C}\right)$ \\
\hline \multirow[t]{2}{*}{ MT1 } & F: TGTCGATATTTAACAACGGGTGG & \\
\hline & R: CGATGCCGGTGATGTTGAA & 58 \\
\hline \multirow[t]{2}{*}{ MT2 } & F: GCATGGCCTACCACCGAATC & \\
\hline & R: AATAGATGCGTGGGTCGTACT & 58 \\
\hline \multirow[t]{2}{*}{ CD73 } & F: TATTGCACTGGGACATTCGGGT & \\
\hline & R: GGTTGCCCATGTTGCATTCTCT & 62 \\
\hline \multirow[t]{2}{*}{ CD105 } & F: CATCCTTGAAGTCCATGTCCTCTT & \\
\hline & R: GCCAGGTGCCATTTTGCTT & 62 \\
\hline \multirow[t]{2}{*}{ Oct-4 } & F: GACAACAATGAGAACCTTCAGGAGA & \\
\hline & R: TTCTGGCGCCGGTTACAGAACCA & 62 \\
\hline \multirow[t]{2}{*}{ Sox2 } & F: AACCAAGACGCTCATGAAGAAG & \\
\hline & R: GCGAGTAGGACATGCTGTAGGT & 62 \\
\hline \multirow[t]{2}{*}{ Nanog } & F: ATAGCAATGGTGTGACGCAG & \\
\hline & R: GATTGTTCCAGGATTGGGTG & 62 \\
\hline \multirow[t]{2}{*}{ GAPDH } & F: GTGGTCTCCTCTGACTTCAACA & \\
\hline & R: CTCTTCCTCTTGTGCTCTTGCT & 62 \\
\hline \multirow[t]{2}{*}{$\mathrm{p} 21$} & F: GCGATGGAACTTCGACTTTG & \\
\hline & R: CGTTTTCGACCCTGAGAGAGTC & 60 \\
\hline \multirow[t]{2}{*}{ Dlx5 } & F: ACCATCCGTCTCAGGAATCG & \\
\hline & R: ACCTTCTCTGTAATGCGGCC & 60 \\
\hline \multirow[t]{2}{*}{ Runx2 } & F: GACCAGTCTTACCCCTCCTACC & \\
\hline & R: CTGCCTGGCTCTTCTTACTGAG & 58 \\
\hline \multirow[t]{2}{*}{ BMP7 } & F: CCAACGTCATCCTGAAGAAATAC & \\
\hline & R: GCTTGTAGGATCTTGTTCATTGG & 60 \\
\hline \multirow[t]{2}{*}{ Sox9 } & F: GCCGGGCAAGGCTGACCTGAAG & \\
\hline & R: TTCTGGTGGTCGGTGTAGTCGT & 61 \\
\hline \multirow[t]{2}{*}{ PPARG } & F: TCTCTCCGTAATGGAAGACC & \\
\hline & R: GCATTATGAGACATCCCCA & 62 \\
\hline \multirow[t]{2}{*}{ CEBPA } & F: CCAAGAAGTCGGTGGACAAGAA & \\
\hline & R: TCATTGTCACTGGTCAGCTCCA & 62 \\
\hline \multirow[t]{2}{*}{ IL-6 } & F: ATGAACTCCTTCTCCACAAGC & \\
\hline & R: GTTTTCTGCCAGTGCCTCTTTG & 60 \\
\hline \multirow[t]{2}{*}{ IL-10 } & F: ACCTGGTAGAAGTGATGCCCCAGGCA & \\
\hline & R: CTATGCAGTTGATGAAGATGTCAA & 58 \\
\hline
\end{tabular}

by a melting curve program. Primers used are listed in Table I. Gene expression was normalized to that of GAPDH and analyzed using advanced relative quantification based on the E-method provided by Roche Applied Science (23). Data were expressed as the mean \pm SD of three independent experiments.

Immunostaining. The cells were fixed in $4 \%$ paraformaldehyde solution (Biosesang, Inc.) for $20 \mathrm{~min}$ on ice. After washing with PBS containing $0.1 \%$ bovine serum albumin (Sigma-Aldrich; Merck KGaA) for $10 \mathrm{~min}$, cells were incubated in permeabilization/blocking solution (PBS containing $0.3 \%$ Triton X-100 and $10 \% \mathrm{FBS}$ ) for $10 \mathrm{~min}$ at room temperature. The following primary antibodies were then added at $4^{\circ} \mathrm{C}$ for 24 h: Human MT1 (1:200; Santa Cruz Biotechnology, Inc.; cat. no. sc-390328) and human MT2 (1:200; Abcam; cat. no. ab203346). After washing for $10 \mathrm{~min}$, fluorescently-labeled secondary antibodies were added as follows: Anti-mouse Ig immunoglobulin (Ig) G Alexa Fluor 488 and anti-rabbit IgG Alexa Fluor 594 (cat nos. A11029 and A11012 respectively; both 1:400; Thermo Fisher Scientific, Inc.) at room temperature for $30 \mathrm{~min}$. After washing for $10 \mathrm{~min}$, cells were stained with DAPI (1:1,000; Sigma-Aldrich; Merck KGaA) for 5 min. Fluorescence images were obtained using a confocal laser scanning microscope (Carl-Zeiss LSM 700 Exciter; Zeiss $\mathrm{GmbH}$ ). One representative image of three independent experiments is shown. 
Colony-forming efficiency (CFE) assay. To evaluate the stemness of AdMSCs, CFE assays were performed. Approximately $2 \times 10^{3}$ cells at passage $5-10$ were seeded in $100 \mathrm{~mm}$ dishes (Corning Inc.), and the cells were cultured for 2 weeks. Whenever the media were replaced, melatonin and luzindole were added to the test group. After 2 weeks, the media were removed and the cells were washed twice in PBS. Then, the cells were stained with $3 \%$ crystal violet (Sigma-Aldrich; Merck KGaA) in methanol for $10 \mathrm{~min}$ at room temperature, and stained colonies ( $>50$ cells) were counted. Data were expressed as the mean \pm SD of three independent experiments.

$\beta$-galactosidase (gal) assay. $\beta$-gal assays were performed when cells exhibited typical senescent phenotypes, with an enlarged and flattened cell morphology after 15 passages. To identify $\beta$-gal activity in senescent cells, a senescence detection kit was used (BioVision, Inc.), according to the manufacturer's instructions. After washing with PBS, fixed cells were incubated with $\beta$-gal staining reagent overnight at $37^{\circ} \mathrm{C}$. The number of $\beta$-gal-stained cells (blue color) was counted under a light microscope (IX71; Olympus Corporation). Data were expressed as the mean \pm SD of three independent experiments.

Adipogenic differentiation. To differentiate AdMSCs into adipocytes, cells at passage 5-10 were induced in adipogenic differentiation medium (Lonza Group, Ltd.) for 3 weeks. The media were changed every 3-4 days. Melatonin and/or luzindole were added to the tested cells whenever the media were replaced. The differentiated cells were washed with PBS, then incubated with $10 \%$ formalin (Sigma-Aldrich; Merck $\mathrm{KGaA}$ ) for $30 \mathrm{~min}$ at room temperature. After washing, $60 \%$ isopropanol was dispensed. Oil Red $\mathrm{O}$ solution in distilled water was added to the cells for $10 \mathrm{~min}$. After washing with tap water, images of the red-stained cells were obtained using an inverted light phase-contrast microscope (IX71; Olympus Corporation). To obtain quantitative data regarding adipogenesis, absorbance was measured at $500 \mathrm{~nm}$ after destaining with isopropanol. Data were expressed as the mean \pm SD of three independent experiments.

$T$ cell proliferation assay. To investigate the effects of melatonin on the suppression of $\mathrm{T}$ cell proliferation, $1 \times 10^{5}$ human peripheral blood mononuclear cells (obtained from the same donors) were co-cultured with $1 \times 10^{4}$ AdMSCs in 96-well plates. Then, $10 \mu \mathrm{M}$ of melatonin and $5 \mu \mathrm{M}$ of luzindole were added to the cells, and $10 \mu \mathrm{g} / \mathrm{ml}$ phytohaemagglutinin (Sigma-Aldrich; Merck KGaA) was applied for activation of $\mathrm{T}$ cells. After 3 days, the inhibition of T cells was determined using the EZ-cytox proliferation assay kit, according to the manufacturer's instructions. Data were expressed as the mean \pm SD of three independent experiments.

Statistical analysis. Quantitative data were expressed as means \pm SD. Statistical comparisons were performed using Student's t-test or one-way analysis of variance with post hoc Bonferroni correction using SPSS software v18 (SPSS, Inc.). $\mathrm{P}<0.05$ was considered to indicate a statistically significant difference.

\section{Results}

Melatonin treatment enhances the proliferation of AdMSCs and induces melatonin receptor expression. To investigate the effects of melatonin on the viability and proliferation rates of AdMSCs, a water-soluble tetrazolium salt in vitro assay system was used. The cell numbers of AdMSCs were increased following melatonin incubation, without any reduction in cell viability. After 3 days of incubation, the dose $10 \mu \mathrm{M}$ melatonin resulted in the highest proliferation rate in the treated AdMSCs (Fig. 1A). Therefore, the dose of $10 \mu \mathrm{M}$ melatonin was selected for subsequent experiments. Melatonin-treated AdMSCs exhibited a fibroblast-like spindle shape, similar to that of untreated cells (Fig. 1B).

To identify changes involving the melatonin receptor, the expression levels of MT1 and MT2 were detected by RT-qPCR. When AdMSCs were treated with melatonin, the mRNA expression levels of MT1 and MT2 were upregulated compared with those in untreated cells, although these changes were not significant statistically (Fig. 1C). In order to confirm that melatonin treatment induced the expression levels of both the melatonin receptors, their protein expression was evaluated by immunofluorescence with specific antibodies. MT1 and MT2 were strongly expressed in melatonin-treated cells after 3 days of incubation, compared with the control untreated cell group (Fig. 1D). These results indicated that melatonin facilitated AdMSC proliferation and upregulated MT1 and MT2 expression and abundance.

Melatonin suppresses cellular senescence of AdMSCs and induces SRY-box transcription factor 2 (Sox2). The mRNA expression levels of CD73 (also known as ecto-5'-nucleotidase) and CD105 (also known as endoglin), which are known key markers of MSCs, were detected, in order to determine whether melatonin-treated AdMSCs retained MSC-like properties. RT-PCR analysis revealed that melatonin-treated AdMSCs retained the expression of key markers of MSCs (Fig. 1A). Next, the expression levels of octamer-binding transcription factor 4 (Oct-4), Sox 2 and nanog homeobox (Nanog), which are known key factors for maintenance of stem cell pluripotency, were analyzed, in order to investigate the stemness status of AdMSCs following melatonin treatment. Sox 2 was markedly upregulated in the melatonin-treated AdMSCs, while the expression levels of Oct-4 and Nanog genes remained unaltered compared with those in the control group (Fig. 2A). Subsequently, the effects of melatonin were investigated on the colony formation ability of AdMSCs, and the results demonstrated that melatonin-treated AdMSCs exhibited increased self-renewal capacity compared with the control group (Fig. 2B).

Next, the present study investigated whether melatonin inhibited the replicative senescence of AdMSCs in long-term culture. Melatonin-treated AdMSCs exhibited a significant reduction in the proportion of $\beta$-gal-stained cells compared with the control group (Fig. 2C). Furthermore, the inhibition of cellular senescence was confirmed RT-qPCR results demonstrating a significant downregulation of the $\mathrm{p} 21$ gene, which is crucial for MSC senescence (24), in the melatonin-treated AdMSCs (Fig. 2D). Taken together, these results indicated that melatonin reduced the replicative senescence of AdMSCs by modulating the expression levels of Sox 2 and p21. 

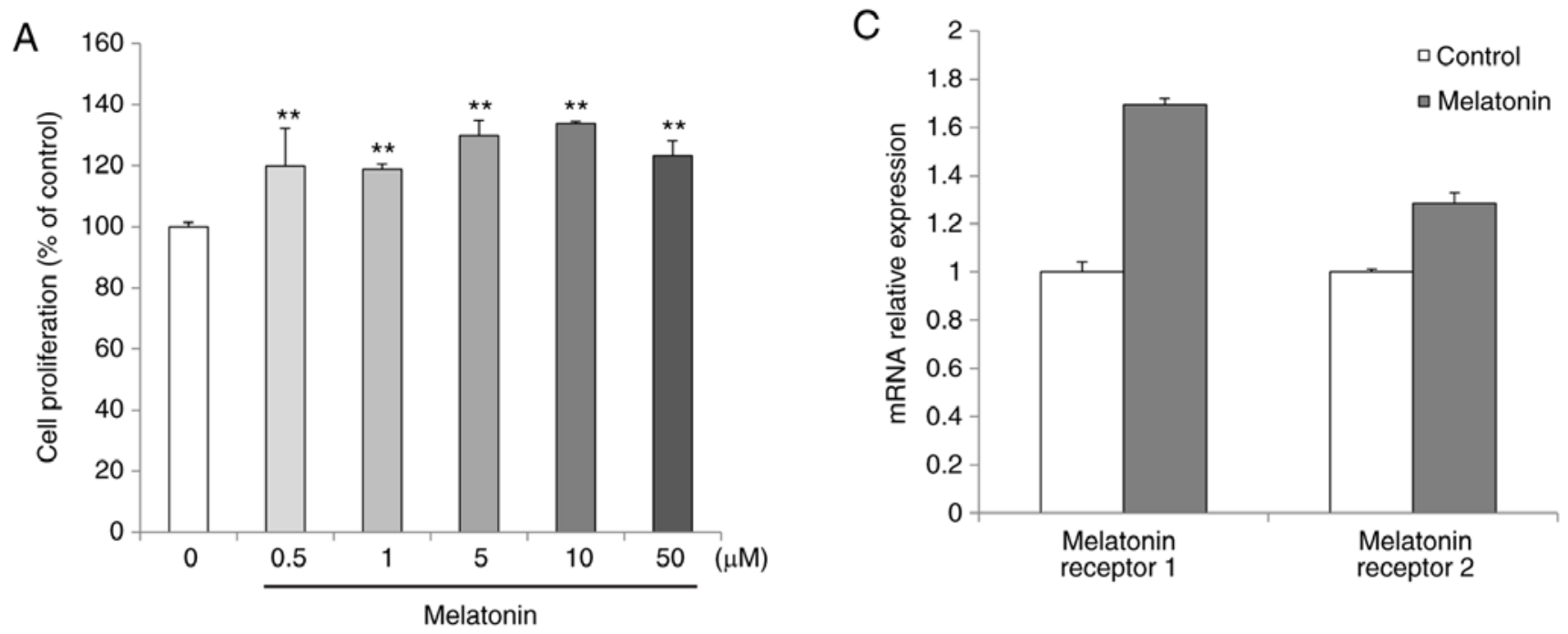

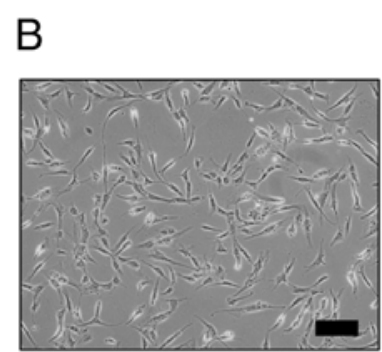

Control

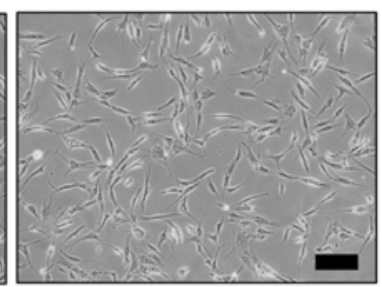

Melatonin
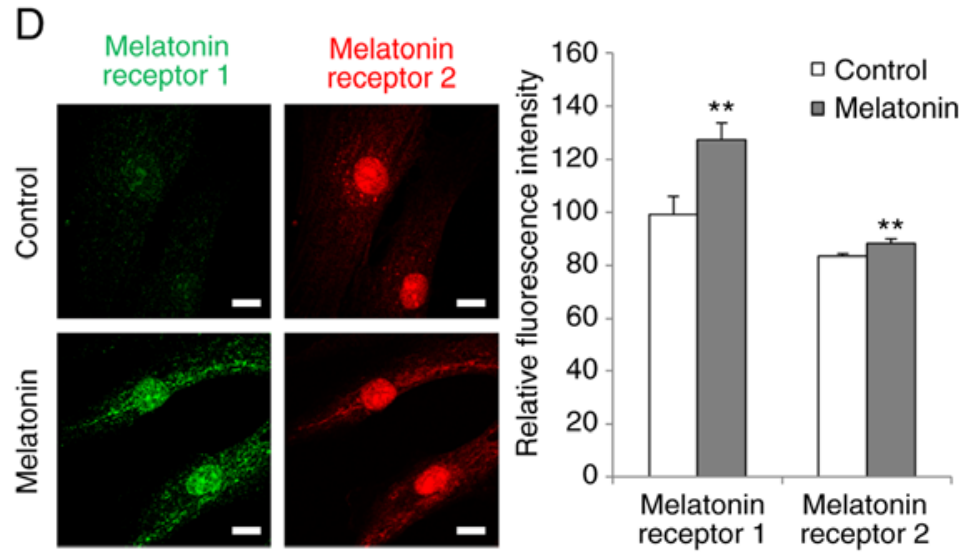

Figure 1. Effects of melatonin on the proliferation of AdMSCs. (A) AdMSCs were cultured with varying concentrations (0.5-50 $\mu \mathrm{M})$ of melatonin for 3 days Cell proliferation was determined using an EZ-cytox assay based on WST. (B) Cell morphology images were captured before and after treatment with $10 \mu \mathrm{M}$ melatonin for 3 days (scale bar, $200 \mu \mathrm{m}$; magnification, x100). (C) Expression of melatonin receptors type 1 and 2 was analyzed by reverse-transcription quantitative PCR. (D) Immunofluorescence staining was performed to examine the protein expression levels of melatonin receptors in untreated cells and melatonin-treated cells (scale bar, $50 \mu \mathrm{m}$; magnification, x63). A representative image of three independent experiments is shown. Data are presented as the mean \pm SD of three independent experiments. ${ }^{* *} \mathrm{P}<0.01$ compared with control untreated cells. AdMSCs, adipose-derived mesenchymal stem cells.

Melatonin affects the differentiation capacity and anti-inflammatory activity of AdMSCs. To investigate whether melatonin affects the in vitro tri-lineage differentiation capacity of AdMSCs into osteoblasts, chondrocytes and adipocytes, the mRNA expression levels of key differentiation marker genes were analyzed. The expression levels of distal-less homeobox 5 (Dlx5) and runt-related transcription factor 2 (Runx2), key transcription factors for osteogenesis, and the expression levels of bone morphogenetic protein 7 (BMP7) and SRY-box transcription factor 9 (Sox 9), markers of chondrogenesis, remained unaltered following melatonin treatment (Fig. 3A). Notably, the expression levels of CCAAT enhancer binding protein $\alpha$ (CEBPA), a key transcription factor for adipogenesis, were markedly reduced in the melatonin-treated AdMSCs (Fig. 3A). The expression levels of the peroxisome proliferator activated receptor $\gamma$ (PPARG) gene were unchanged. To further examine the effects of melatonin in adipogenesis of AdMSCs, in vitro adipogenic differentiation assays were performed. The results demonstrated that melatonin disrupted AdMSC adipogenesis, as evidenced by reduced Oil red $\mathrm{O}$ staining in the melatonin-treated AdMSCs (Fig. 3B), indicating that melatonin exhibited specific anti-adipogenic effects.
To assess the immunomodulatory effects of melatonin-treated AdMSCs, a co-culture system of T cells and AdMSCs was used. T cell proliferation was slightly inhibited in the presence of melatonin-treated AdMSCs, although this effect was not statistically significant (Fig. 3C). The immunomodulation of MSCs is mediated by various cytokines, such as interleukin (IL)-6, as a pro-inflammatory cytokine, and IL-10, as an anti-inflammatory cytokine (25). In the present study, a significant decrease in IL-6 expression was observed following melatonin treatment, while the mRNA expression levels of IL-10 remained unchanged (Fig. 3D). These results indicated that melatonin-treated AdMSCs may have an anti-inflammatory role via immunomodulation (Fig. 3D).

Effects of melatonin in the presence of the melatonin receptor inhibitor, luzindole. Next, the present study aimed to identify whether the effects of melatonin on AdMSCs were mediated by the melatonin receptor pathway. Accumulating evidence from studies using cell or animal models have suggested that luzindole acts as a potent inhibitor of melatonin receptors $(15,26)$. Therefore, the effects of melatonin on AdMSCs were investigated in the presence of the melatonin receptor 

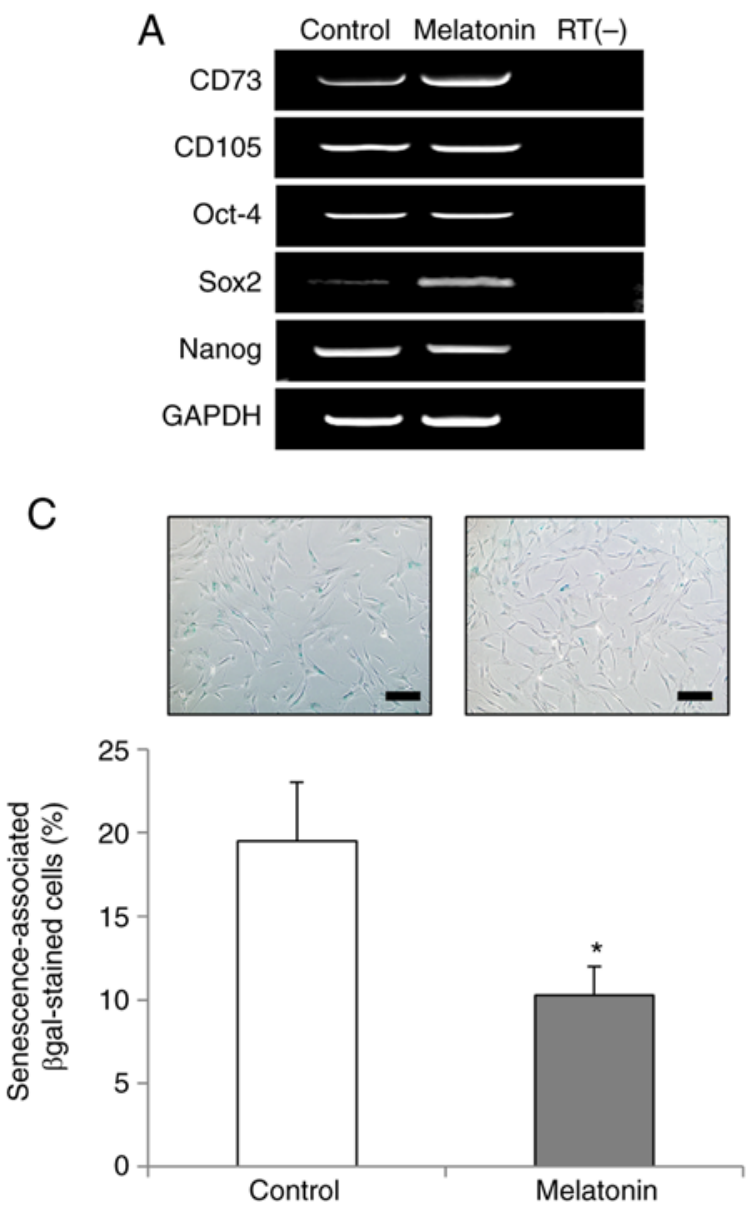
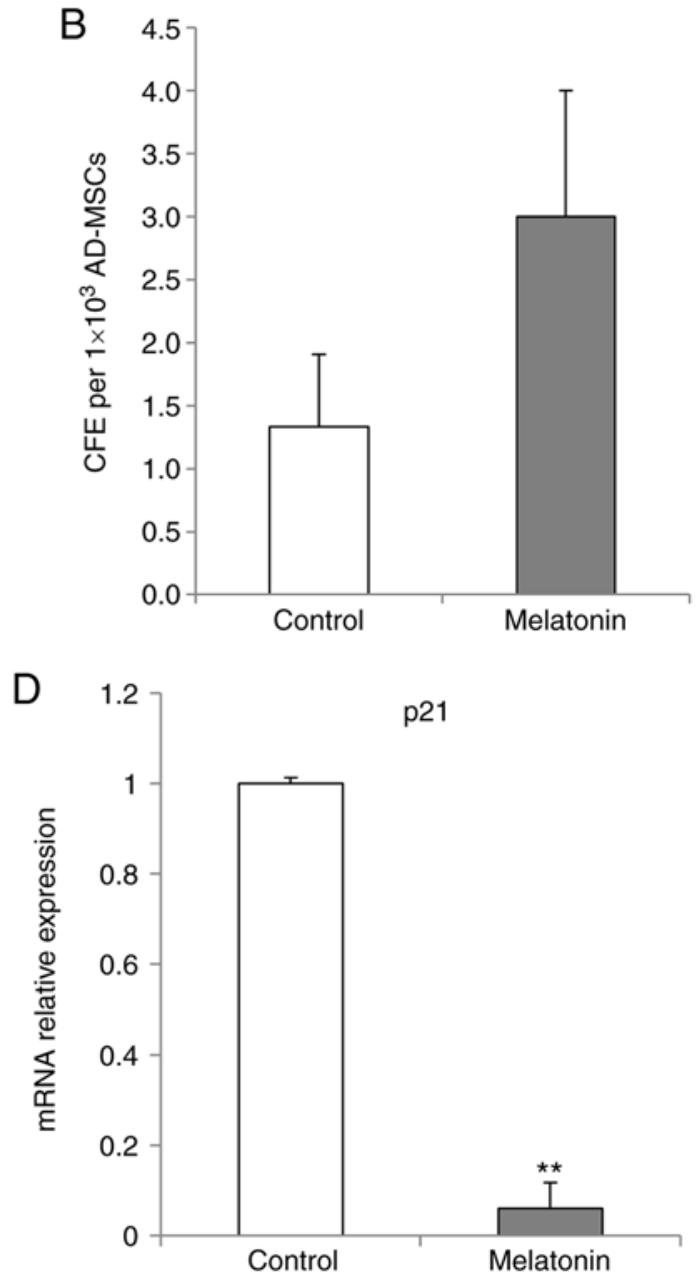

Figure 2. Effects of melatonin on the senescence of AdMSCs. (A) Gene expression for MSCs and stemness was evaluated through reverse transcription-PCR analysis. RT(-) indicates a negative control using water alone as the reaction input. (B) Self-renewal capacity was assessed through a colony formation assay. (C) Cell senescence was confirmed by $\beta$-galactosidase staining after long-term culture ( $>15$ passages). A representative image of three independent experiments is shown (scale bar, $200 \mu \mathrm{m}$; magnification, x100). (D) mRNA expression levels of p21 were analyzed by quantitative PCR. Data are presented as the mean \pm SD of three independent experiments. ${ }^{*} \mathrm{P}<0.05$ and ${ }^{* *} \mathrm{P}<0.01$. AdMSCs, adipose-derived mesenchymal stem cells; MSCs, mesenchymal stem cells; Oct-4, octamer-binding transcription factor 4; Sox2, SRY-box transcription factor 2; Nanog, nanog homeobox; CFE, colony-forming efficiency.

antagonist luzindole. Firstly, luzindole was added as a pretreatment for $24 \mathrm{~h}$ to inhibit melatonin receptors, and then the cells were treated with melatonin. Morphological changes were not observed despite luzindole treatment during the 3 days of the experiment (data not shown). The results revealed that the mRNA expression levels of melatonin type 1 and 2 receptors, otherwise upregulated by melatonin, were significantly inhibited by luzindole (Fig. 4A). Furthermore, the results of immunofluorescence staining confirmed at the protein level that upregulation of melatonin receptors was inhibited by luzindole treatment (Fig. 4B).

Next, the effects of luzindole treatment on AdMSC proliferation were investigated. The results demonstrated that proliferation of AdMSCs, accelerated by melatonin, was reduced following luzindole treatment (Fig. 4C). In addition, treatment of AdMSCs with luzindole for 3 days significantly increased the mRNA expression levels of p21 (Fig. 4D). Subsequently, the present study investigated whether luzindole reduced the self-renewal capacity of melatonin-treated AdMSCs, using the colony formation assay. AdMSCs cultured with melatonin exhibited a significant increase in the number of colonies, while this effect was significantly revered following luzindole treatment (Fig. 4E). Finally, as presented in Fig. 4F, the percentage of $\beta$-gal-positive cells was decreased by melatonin treatment, whereas this effect was reversed in the presence of luzindole. These results demonstrated that the enhanced proliferation of melatonin-treated AdMSCs was mediated by melatonin receptor signaling.

The present results revealed that melatonin inhibited AdMSC adipogenesis (Fig. 3B). During in vitro adipogenic differentiation, the amount of lipid accumulation in melatonin-treated cells was less compared to that in the control group, while the lipid content in luzindole-treated cells was equivalent to that in control cells (Fig. 5A). Quantification of the staining results confirmed the effects of melatonin and luzindole during adipogenesis of AdMSCs (Fig. 5A). In addition, the effect of luzindole was assessed on the immunomodulation-related anti-inflammatory ability of AdMSCs. Melatonin-treated cells inhibited the proliferation of $\mathrm{T}$ cells compared with that of the control group (Fig. 5B). However, luzindole treatment reversed the inhibitory effects of melatonin on the growth of T cells (Fig. 5B). Next, the effects of luzindole were analyzed on the anti-inflammatory 

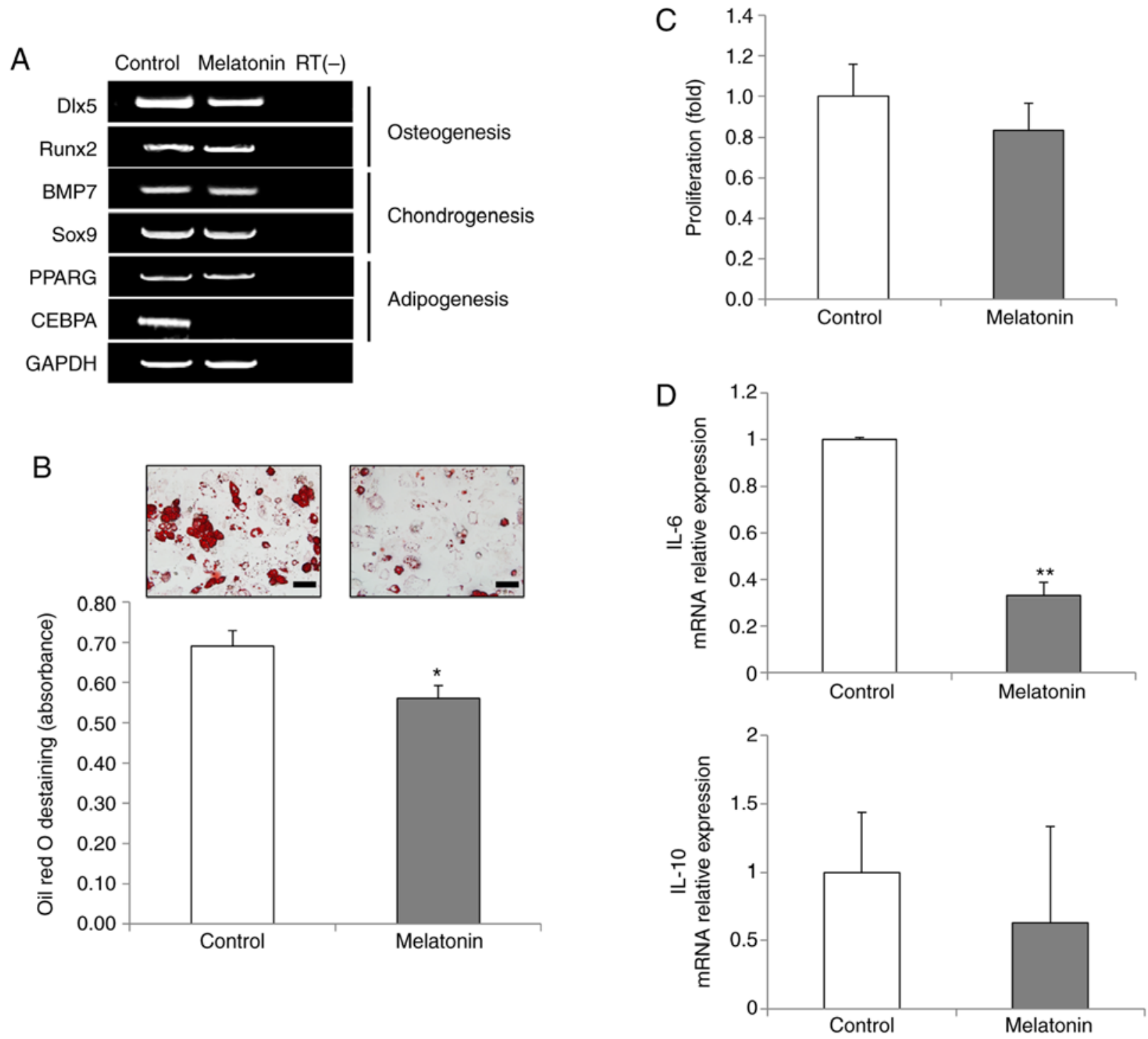

Figure 3. Effects of melatonin on the differentiation capacity and immunomodulation of AdMSCs. (A) Reverse transcription-PCR analysis of key transcription factors for osteogenesis, chondrogenesis and adipogenesis in untreated cells and in $10 \mu \mathrm{M}$ melatonin-treated cells. One representative of three independent experiments is shown. RT(-) indicates a negative control using water alone as the reaction input. (B) Adipogenic differentiation capacity was analyzed by Oil Red O staining (scale bar, $50 \mu \mathrm{m}$; magnification, x400). For quantitative analysis, absorbance was measured at $500 \mathrm{~nm}$ after destaining. (C) Inhibition of activated mononuclear cells was evaluated through EZ-cytox assays. Phytohaemagglutinin-induced mononuclear cells were co-cultured with untreated or melatonin-treated AdMSCs for 3 days. (D) Relative mRNA expression levels of inflammation-related factors IL- 6 and IL-10 were evaluated by quantitative PCR. Data are presented as the mean \pm SD of three independent experiments. ${ }^{*} \mathrm{P}<0.05$ and ${ }^{* *} \mathrm{P}<0.01$. AdMSCs, adipose-derived mesenchymal stem cells; IL, interleukin; Dlx5, distal-less homeobox 5; Runx2, runt-related transcription factor 2; BMP7, bone morphogenetic protein 7; Sox9, SRY-box transcription factor 9; PPARG, peroxisome proliferator activated receptor $\gamma$; CEBPA, CCAAT enhancer binding protein $\alpha$.

properties of melatonin-treated AdMSCs. Compared with the control group, the expression levels of IL-6 decreased in the melatonin-treated cells, whereas IL- 6 expression in activated $\mathrm{T}$ cells was increased after luzindole treatment (Fig. 5C). Of note, a significant reduction in IL-10 expression was observed in cells treated with melatonin and luzindole (Fig. 5C). Taken together, these results indicated that the activation of melatonin receptors type 1 and 2 was involved in mediating the positive effects of melatonin on the proliferative activity, self-renewal capacity and immunomodulation of AdMSCs.

\section{Discussion}

Melatonin has been reported to have critical roles in various physiological and pathological processes in vitro and in vivo in stem cell-based regenerative medicine (16). In numerous experimental reports, melatonin displayed anti-inflammatory effects by modulating the balance between pro-inflammatory and anti-inflammatory cytokines in stem cells $(27,28)$. A recent study showed that the injection of melatonin-treated MSCs into ischemic rat brain significantly enhances the survival of MSCs and improves their therapeutic efficacy (15). In addition, melatonin has been demonstrated to influence the proliferative activity of a variety of cell types, including neural stem cells and MSCs $(13,29,30)$; however, the mechanisms through which the biological actions of AdMSCs are influenced by melatonin have not been extensively studied to date.

Melatonin, known as an activator of the ERK pathway, increases cell proliferation (31). However, the optimal concentration of melatonin depends on the cell type $(32,33)$. In the 

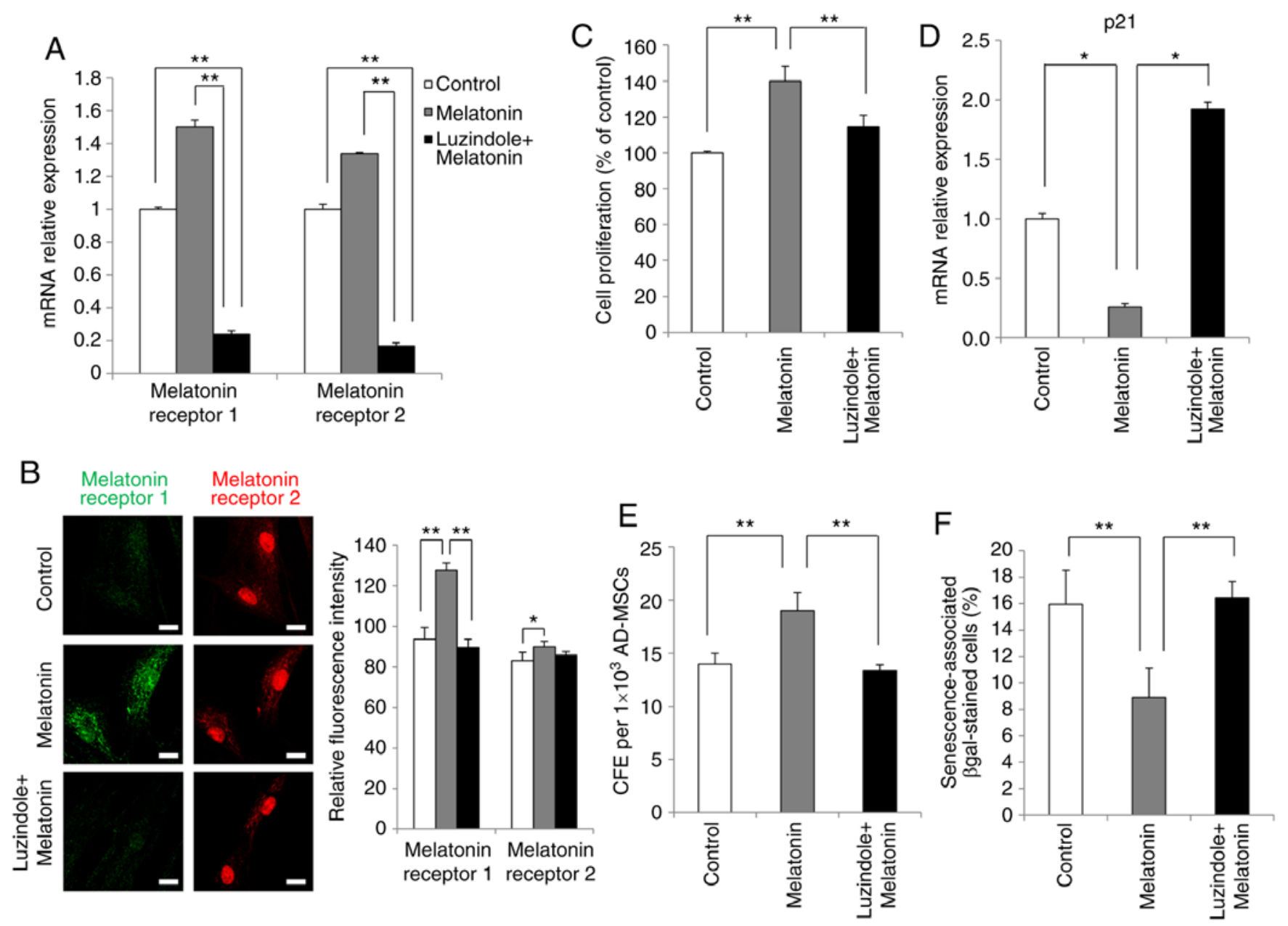

Figure 4. Effects of luzindole on cell proliferation and senescence in melatonin-treated AdMSCs. (A) The expression levels of melatonin receptors type 1 and 2 were determined by quantitative PCR after treatment with $10 \mu \mathrm{M}$ melatonin and/or $5 \mu \mathrm{M}$ luzindole for 3 days. (B) The protein expression of melatonin receptors was confirmed using confocal microscopy (scale bar, $50 \mu \mathrm{m}$; magnification, x63). (C) The growth rate of AdMSCs was measured by EZ-Cytox assays after treatment with $10 \mu \mathrm{M}$ melatonin and/or $5 \mu \mathrm{M}$ luzindole for 3 days. (D) mRNA expression levels of the p21 gene. (E) Self-renewal capacity was evaluated by a colony formation assay. The number of colonies that formed per 1,000 cells was counted. (F) Senescence-associated $\beta$-galactosidase assay of AdMSCs treated with melatonin and/or luzindole after long-term culture. Data are presented as the mean $\pm \mathrm{SD}$ of three independent experiments. ${ }^{*}<0.05$ and ${ }^{* *} \mathrm{P}<0.01$, with comparisons indicated by brackets. AdMSCs, adipose-derived mesenchymal stem cells; CFE, colony-forming efficiency.

current study, melatonin treatment increased the cell proliferation rate in all dose groups $(0.5,1,5,10$ and $50 \mu \mathrm{M})$. The maximal effect was observed at $10 \mu \mathrm{M}$ melatonin. Notably, melatonin exhibited maximal effects after daily exposure, because it has a short half-life. Thus, it was speculated that the exposure period of melatonin is possibly an important factor contributing to its effectivess. Melatonin acts via the G protein-coupled receptors MT1 and MT2, and interacts with intracellular proteins (34). Treatment with $10 \mu \mathrm{M}$ melatonin upregulated the expression levels of MT1 and MT2. Furthermore, the results confirmed, at the mRNA and the protein level, that melatonin acted through both melatonin receptors. MT1 is normally localized on the cell membrane. However, in the present study MT1 expression was observed both in the cytoplasm and the nucleus. The experiments for the detection of specific localization in cell culture may vary by the protocol or type of reagents. Future investigations are underway to examine the localization of melatonin receptors in MSCs in detail.

Replicative senescence of MSCs during in vitro expansion for clinical application reduces therapeutic efficacy of the cells by decreasing their viability (20). Previously, Yoon et al (35) demonstrated that activation of Sox 2 significantly improved the multi-potentiality and proliferation of MSCs. Melatonin is known to act as an anti-aging agent, as reported in numerous studies $(36,37)$. It has also been recently reported that treatment with melatonin during long-term in vitro expansion preserved $>80 \%$ of the self-renewal capacity of MSCs by retaining their stemness (16). The present results suggested that melatonin inhibited replicative senescence by upregulating Sox 2 expression. MSCs, at late passage, exhibited increased expression of p21 and decreased proliferative activity (38). p21, a key molecule that regulates the cell cycle, is known to serve a critical role in mediating cellular senescence of MSCs (24). The present results demonstrated that inhibition of $\mathrm{p} 21$ expression by melatonin reversed the senescent phenotype of AdMSCs. In addition, pro-inflammatory cytokines, such as IL-6, tumor necrosis factor (TNF)- $\alpha$ and IL-1 $\beta$, are well-known to induce cellular senescence in diverse cell types, including MSCs (39). In the present study, melatonin-treated AdMSCs had significantly decreased IL-6 mRNA expression levels. The current data suggested that melatonin may be considered as a critical 
A
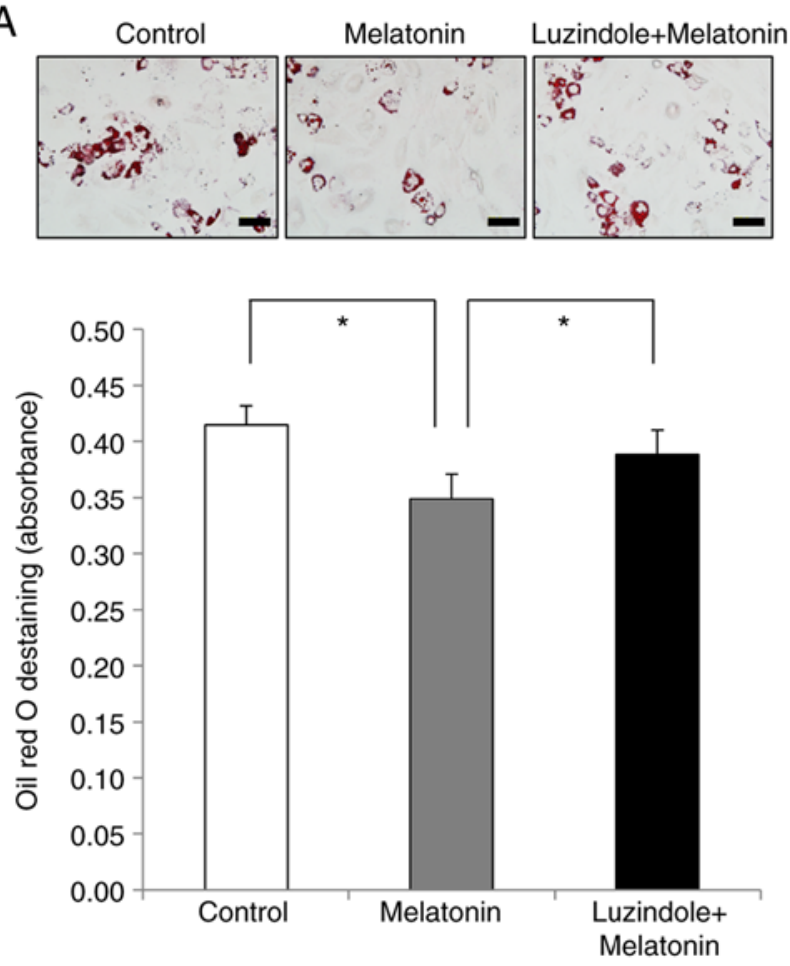
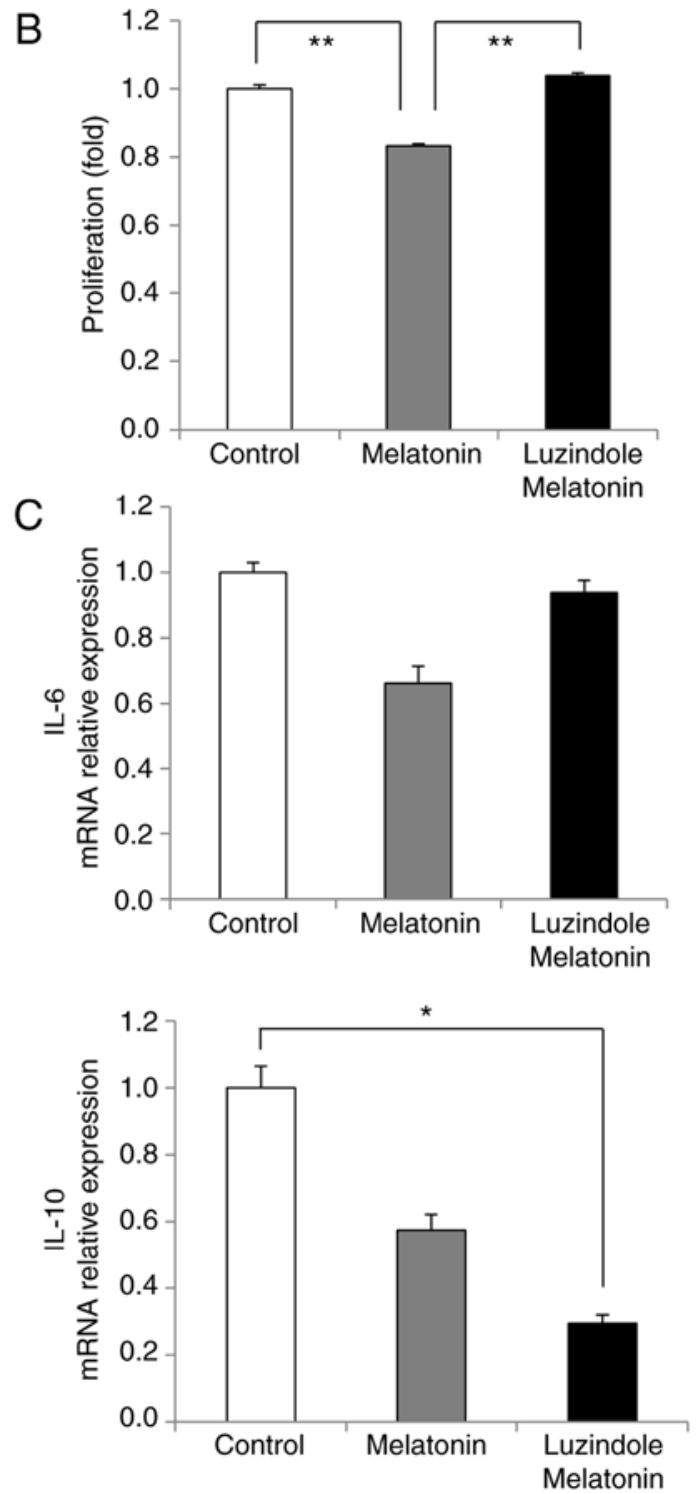

Figure 5. Effects of luzindole on adipogenesis and immunomodulation in melatonin-treated AdMSCs. (A) Adipogenic differentiation capacity of AdMSCs was evaluated after treatment with $10 \mu \mathrm{M}$ melatonin and/or $5 \mu \mathrm{M}$ luzindole for 14 days. One representative of three independent experiments is shown. Absorbance was measured after differentiation for quantitative analysis. (B) Proliferation of mononuclear cells co-cultured with melatonin-treated AdMSCs and melatonin-treated AdMSCs treated with luzindole was determined after 3 days. (C) Relative mRNA expression levels of immunomodulation-related factors IL- 6 and IL-10 were analyzed by quantitative PCR. Data are presented as the mean \pm SD of three independent experiments. ${ }^{*} \mathrm{P}<0.05$ and ${ }^{* *} \mathrm{P}<0.01$, with comparisons indicated by brackets. AdMSCs, adipose-derived mesenchymal stem cells; IL, interleukin.

factor for the expansion of AdMSCs by inhibiting cellular senescence. These findings are consistent with results of previous studies (16).

Zhang et al (30) suggested that melatonin inhibits adipogenesis and enhances the osteogenesis of MSCs by suppressing PPAR $\gamma$ and enhancing Runx 2 gene expression. The present data demonstrated that melatonin treatment inhibited adipogenic differentiation in AdMSCs by suppressing CEBPA gene expression, which is a key transcription factor in adipogenesis, whereas osteogenic differentiation was induced regardless of exposure to melatonin. This result indicated that CEBPA may represent a key factor that regulates adipogenesis. We postulated that the effect of melatonin on pluripotency of AdMSCs may depend on the specific cell type involved and the culture conditions. For example, a previous study reported that melatonin, at low concentrations, significantly promoted 3T3-L1 cell growth, whereas in another study, melatonin exhibited no significant effects on the proliferation of bovine intramuscular preadipocytes $(40,41)$. Several studies have suggested that stimulation of differentiation potential by melatonin involves melatonin receptor and signaling pathways, including Wnt/catenin, transforming growth factor and mitogen-activated protein kinases, to regulate the expression of critical differentiation factors $(42,43)$. However, the exact mechanisms of the melatonin-mediated regulation of differentiation remain unclear. Obesity is considered to be a result of dysfunctional adipogenesis involving deregulation of adipocyte size and number, and may be associated with differentiation processes affecting stem cell-derived pre-adipocytes (44). Activation of 5'AMP-activated protein kinase (AMPK) inhibits adipogenesis and promotes lipolysis, by suppressing adipogenesis-related gene expression (45). The present study confirmed that melatonin treatment enhanced the 
activity of AMPK in AdMSCs, suggesting that it acted as an activator of AMPK (data not shown). Thus, adipogenic regulation of AdMSCs by melatonin may serve as a novel therapeutic application against fat deposition.

Melatonin, as one of the immunomodulatory factors involved in immune responses, exerts anti-inflammatory effects via the regulation of inflammation-related cytokines (46). Biological effects of melatonin on immune regulation have been validated in vivo and in vitro (47). A previous study has shown that the administration of melatonin decreased inflammatory responses by mediating the levels of immunomodulatory factors, including IL- $1 \beta$, TNF- $\alpha$ and IL-6 (48). The present study demonstrated that treatment with melatonin effectively inhibited $\mathrm{T}$ cell proliferation. This inhibition was associated with decreased levels of IL-6 and IL-10, indicating that their expression may be related to the inhibition of $\mathrm{T}$ cell activity. However, the possible interactions of other immunomodulatory factors and immune cells cannot be excluded. In the present study, the melatonin receptor antagonist luzindole was used to block the effects of melatonin on AdMSCs. The expression levels of melatonin receptors MT1 and MT2 at the mRNA and protein levels could be detected in melatonin-treated AdMSCs, whereas luzindole strongly inhibited the activities of melatonin receptors. Luzindole was demonstrated to completely reverse the positive effects of melatonin on proliferation, self-renewal capacity and immunomodulation, indicating that the beneficial effects of melatonin were receptor-mediated.

In conclusion, the findings of the present study demonstrated that melatonin treatment effectively promoted the proliferation and prevented the replicative senescence of AdMSCs via the melatonin receptors MT1 and MT2. In addition, it was confirmed that melatonin treatment inhibited the expression of the CEBPA gene, a key transcription factor of adipogenic differentiation in MSCs. There was no effect on osteogenic and chondrogenic differentiation. The present study focused predominantly on the examination of adipogenesis of MSCs by melatonin treatment in an AdMSC culture model. The results suggested that melatonin-induced MSCs might be considered in the development of anti-obesity therapy. To improve the therapeutic efficacy of MSCs, several studies have suggested that pre-conditioning of MSCs by hypoxia, natural molecules and growth factors enhances the activity of MSCs $(49,50)$. The greatest advantage of melatonin, a natural small molecule, is that it has no reported side effects. It is, therefore, suggested that melatonin could be used for treating various diseases, including inflammation; however, the mechanisms underlying the beneficial effects of melatonin need to be elucidated in future studies. Future investigations are also needed to explore further the role of melatonin in improving cell therapy using AdMSCs in disease models.

\section{Acknowledgements}

Not applicable.

\section{Funding}

This study was supported by a Jungwon University Research Grant (grant no. 2017-050).

\section{Availability of data and materials}

The data used to support the findings of this study are available from the corresponding author upon request.

\section{Authors' contributions}

SGL and JK planned the project and wrote the manuscript. JSH, SP and JYL performed the experiments, and analysed the data. DWY, BYK and JHK participated in the stem cell experiments and analysed the data. GJK provided stem cells and analysed the data. All authors read and approved the final manuscript.

\section{Ethics approval and consent to participate}

This study was approved by the Institutional Review Board of CHA General Hospital, Seoul, Korea. Written informed consent was obtained from the tissue donors.

\section{Patient consent for publication}

Not applicable.

\section{Competing interests}

The authors declare that they have no competing interests.

\section{References}

1. Rivera-Cruz CM, Shearer JJ, Figueiredo Neto $M$ and Figueiredo ML: The immunomodulatory effects of mesenchymal stem cell polarization within the tumor microenvironment niche. Stem Cells Int 2017: 4015039, 2017.

2. Si Z, Wang X, Sun C, Kang Y, Xu J, Wang X and Hui Y: Adipose-derived stem cells: Sources, potency, and implications for regenerative therapies. Biomed Pharmacother 114: 108765, 2019.

3. Heo JS, Choi Y, Kim HS and Kim HO: Comparison of molecular profiles of human mesenchymal stem cells derived from bone marrow, umbilical cord blood, placenta and adipose tissue. Int J Mol Med 37: 115-125, 2016.

4. Badimon L, Oñate B and Vilahur G: Adipose-derived mesenchymal stem cells and their reparative potential in ischemic heart disease. Rev Esp Cardiol (Engl Ed) 68: 599-611, 2015.

5. Fernández O, Izquierdo G, Fernández V, Leyva L, Reyes V, Guerrero M, León A, Arnaiz C, Navarro G, Páramo MD, et al: Adipose-derived mesenchymal stem cells (AdMSC) for the treatment of secondary-progressive multiple sclerosis: A triple blinded, placebo controlled, randomized phase I/II safety and feasibility study. PLoS One 13: e0195891, 2018.

6. Zhang JJ, Meng X, Li Y, Zhou Y, Xu DP, Li S and Li HB: Effects of melatonin on liver injuries and diseases. Int J Mol Sci 18, 2017.

7. Arendt J: Melatonin, circadian rhythms, and sleep. N Engl J Med 343: 1114-1116, 2000.

8. Li H, Zhang Y, Liu S, Li F, Wang B, Wang J, Cao L, Xia T, Yao Q, Chen $\mathrm{H}$, et al: Melatonin enhances proliferation and modulates differentiation of neural stem cells via autophagy in hyperglycemia. Stem Cells 37: 504-515, 2019.

9. Veneroso C, Tuñón MJ, González-Gallego J and Collado PS: Melatonin reduces cardiac inflammatory injury induced by acute exercise. J Pineal Res 47: 184-191, 2009.

10. Brydon L, Petit L, Delagrange P, Strosberg AD and Jockers R: Functional expression of MT2 (Mel1b) melatonin receptors in human PAZ6 adipocytes. Endocrinology 142: 4264-4271, 2001.

11. Wolden-Hanson T, Mitton DR, McCants RL, Yellon SM, Wilkinson CW, Matsumoto AM and Rasmussen DD: Daily melatonin administration to middle-aged male rats suppresses body weight, intraabdominal adiposity, and plasma leptin and insulin independent of food intake and total body fat. Endocrinology 141: 487-497, 2000. 
12. Alonso-Vale MI, Peres SB, Vernochet C, Farmer SR and Lima FB: Adipocyte differentiation is inhibited by melatonin through the regulation of $\mathrm{C} / \mathrm{EBPbeta}$ transcriptional activity. J Pineal Res 47: 221-227, 2009.

13. Kato H, Tanaka G, Masuda S, Ogasawara J, Sakurai T, Kizaki T, Ohno $\mathrm{H}$ and Izawa T: Melatonin promotes adipogenesis and mitochondrial biogenesis in 3T3-L1 preadipocytes. J Pineal Res 59: 267-275, 2015.

14. Radio NM, Doctor JS and Witt-Enderby PA: Melatonin enhances alkaline phosphatase activity in differentiating human adult mesenchymal stem cells grown in osteogenic medium via MT2 melatonin receptors and the MEK/ERK (1/2) signaling cascade. J Pineal Res 40: 332-342, 2006.

15. Tang Y, Cai B, Yuan F, He X, Lin X, Wang J, Wang Y and Yang GY: Melatonin pretreatment improves the survival and function of transplanted mesenchymal stem cells after focal cerebral ischemia. Cell Transplant 23: 1279-1291, 2014.

16. Shuai Y, Liao L, Su X, Yu Y, Shao B, Jing H, Zhang X, Deng Z and Jin Y: Melatonin treatment improves mesenchymal stem cells therapy by preserving stemness during long-term in vitro expansion. Theranostics 6: 1899-1917, 2016.

17. Mias C, Trouche E, Seguelas MH, Calcagno F, Dignat-George F, Sabatier F, Piercecchi-Marti MD, Daniel L, Bianchi P, Calise D, et al: Ex vivo pretreatment with melatonin improves survival, proangiogenic/mitogenic activity, and efficiency of mesenchymal stem cells injected into ischemic kidney. Stem Cells 26 1749-1757, 2008.

18. Zhou L, Chen X, Liu T, Gong Y, Chen S, Pan G, Cui W, Luo ZP, Pei M, Yang $\mathrm{H}$ and $\mathrm{He} F$ : Melatonin reverses $\mathrm{H}_{2} \mathrm{O}_{2}$-induced premature senescence in mesenchymal stem cells via the SIRT1-dependent pathway. J Pineal Res 59: 190-205, 2015.

19. Jones DL and Wagers AJ: No place like home: Anatomy and function of the stem cell niche. Nat Rev Mol Cell Biol 9: 11-21, 2008.

20. Heo JS, Kim HO, Song SY, Lew DH, Choi Y and Kim S: Poly-L-lysine prevents senescence and augments growth in culturing mesenchymal stem cells ex vivo. Biomed Res Int 2016: 8196078,2016

21. Heo JS, Lee SG and Kim HO: The flavonoid glabridin induces OCT4 to enhance osteogenetic potential in mesenchymal stem cells. Stem Cells Int 2017: 6921703, 2017.

22. Shaw J, Dale I, Hemsley P, Leach L, Dekki N, Orme JP, Talbot V, Narvaez AJ, Bista M, Martinez Molina D, et al: Positioning high-throughput CETSA in early drug discovery through screening against B-Raf and PARP1. SLAS Discov 24: 121-132, 2019.

23. Soong R, Beyser K, Basten O, Kalbe A, Rueschoff J and Tabiti K: Quantitative reverse transcription-polymerase chain reaction detection of cytokeratin 20 in noncolorectal lymph nodes. Clin Cancer Res 7: 3423-3429, 2001.

24. Gu Z, Jiang J, Tan W, Xia Y, Cao H, Meng Y, Da Z, Liu H and Cheng C: p53/p21 Pathway involved in mediating cellular senescence of bone marrow-derived mesenchymal stem cells from systemic lupus erythematosus patients. Clin Dev Immunol 2013: 134243, 2013.

25. Wang M, Yuan Q and Xie L: Mesenchymal stem cell-based immunomodulation: Properties and clinical application. Stem Cells Int 2018: 3057624, 2018.

26. Fang J, Yan Y, Teng X, Wen X, Li N, Peng S, Liu W, Donadeu FX, Zhao S and Hua J: Melatonin prevents senescence of canine adipose-derived mesenchymal stem cells through activating NRF2 and inhibiting ER stress. Aging (Albany NY) 10: 2954-2972, 2018.

27. $\mathrm{Hu} \mathrm{C}$ and Li L: Melatonin plays critical role in mesenchymal stem cell-based regenerative medicine in vitro and in vivo. Stem Cell Res Ther 10: 13, 2019.

28. Zhang S, Chen S, Li Y and Liu Y: Melatonin as a promising agent of regulating stem cell biology and its application in disease therapy. Pharmacol Res 117: 252-260, 2017

29. Liu X, Gong Y, Xiong K, Ye Y, Xiong Y, Zhuang Z, Luo Y, Jiang $\mathrm{Q}$ and $\mathrm{He} \mathrm{F}$ : Melatonin mediates protective effects on inflammatory response induced by interleukin-1 beta in human mesenchymal stem cells. J Pineal Res 55: 14-25, 2013.

30. Zhang L, Su P, Xu C, Chen C, Liang A, Du K, Peng Y and Huang D: Melatonin inhibits adipogenesis and enhances osteogenesis of human mesenchymal stem cells by suppressing PPAR $\gamma$ expression and enhancing Runx 2 expression. J Pineal Res 49: 364-372, 2010

31. Roberts P: Heroes for the past and present: A century of remembering Amundsen and Scott. Endeavour 35: 142-150, 2011.
32. Bai C, Gao Y, Zhang X, Yang W and Guan W: Melatonin promotes self-renewal of nestin-positive pancreatic stem cells through activation of the MT2/ERK/SMAD/nestin axis. Artif Cells Nanomed Biotechnol 46: 62-74, 2018.

33. Lee JH, Han YS and Lee SH: Potentiation of biological effects of mesenchymal stem cells in ischemic conditions by melatonin via upregulation of cellular prion protein expression. J Pineal Res 62 2017.

34. Ekmekcioglu C: Melatonin receptors in humans: Biological role and clinical relevance. Biomed Pharmacother 60: 97-108, 2006.

35. Yoon DS, Kim YH, Jung HS, Paik S and Lee JW: Importance of Sox2 in maintenance of cell proliferation and multipotency of mesenchymal stem cells in low-density culture. Cell Prolif 44: 428-440, 2011

36. Hardeland R: Melatonin and the theories of aging: A critical appraisal of melatonin's role in antiaging mechanisms. J Pineal Res 55: 325-356, 2013.

37. Armstrong SM and Redman JR: Melatonin: A chronobiotic with anti-aging properties? Med Hypotheses 34: 300-309, 1991.

38. Yew TL, Chiu FY, Tsai CC, Chen HL, Lee WP, Chen YJ, Chang MC and Hung SC: Knockdown of p21(Cip1/Waf1) enhances proliferation, the expression of stemness markers, and osteogenic potential in human mesenchymal stem cells. Aging Cell 10: 349-361, 2011

39. Bakker AD, Silva VC, Krishnan R, Bacabac RG, Blaauboer ME, Lin YC, Marcantonio RA, Cirelli JA and Klein-Nulend J: Tumor necrosis factor alpha and interleukin-1beta modulate calcium and nitric oxide signaling in mechanically stimulated osteocytes. Arthritis Rheum 60: 3336-3345, 2009

40. Yang W, Tang K, Wang Y, Zhang Y and Zan L: Melatonin promotes triacylglycerol accumulation via MT2 receptor during differentiation in bovine intramuscular preadipocytes. Sci Rep 7: 15080, 2017.

41. Zwirska-Korczala K, Jochem J, Adamczyk-Sowa M, Sowa P, Polaniak R, Birkner E, Latocha M, Pilc K and Suchanek R: Influence of melatonin on cell proliferation, antioxidative enzyme activities and lipid peroxidation in 3T3-L1 preadipocytes-an in vitro study. J Physiol Pharmacol 56 (Suppl 6): S91-S99, 2005.

42. Sethi S, Radio NM, Kotlarczyk MP, Chen CT, Wei YH, Jockers R and Witt-Enderby PA: Determination of the minimal melatonin exposure required to induce osteoblast differentiation from human mesenchymal stem cells and these effects on downstream signaling pathways. J Pineal Res 49: 222-238, 2010.

43. Luchetti F, Canonico B, Bartolini D, Arcangeletti M, Ciffolilli S, Murdolo G, Piroddi M, Papa S, Reiter RJ and Galli F: Melatonin regulates mesenchymal stem cell differentiation: A review. J Pineal Res 56: 382-397, 2014.

44. Cawthorn WP, Scheller EL and MacDougald OA: Adipose tissue stem cells meet preadipocyte commitment: Going back to the future. J Lipid Res 53: 227-246, 2012.

45. Lo Furno D, Graziano AC, Avola R, Giuffrida R, Perciavalle V, Bonina F, Mannino G and Cardile V: A citrus bergamia extract decreases adipogenesis and increases lipolysis by modulating PPAR levels in mesenchymal stem cells from human adipose tissue. PPAR Res 2016: 4563815, 2016.

46. Mauriz JL, Collado PS, Veneroso C, Reiter RJ and GonzálezGallego J: A review of the molecular aspects of melatonin's anti-inflammatory actions: Recent insights and new perspectives. J Pineal Res 54: 1-14, 2013.

47. Cardinali DP, Esquifino AI, Srinivasan V and PandiPerumal SR: Melatonin and the immune system in aging. Neuroimmunomodulation 15: 272-278, 2008.

48. Mishra A, Paul S and Swarnakar S: Downregulation of matrix metalloproteinase- 9 by melatonin during prevention of alcoholinduced liver injury in mice. Biochimie 93: 854-866, 2011.

49. Han YS, Lee JH, Yoon YM, Yun CW, Noh H and Lee SH: Hypoxia-induced expression of cellular prion protein improves the therapeutic potential of mesenchymal stem cells. Cell Death Dis 7: e2395, 2016.

50. Wu KH, Mo XM, Han ZC and Zhou B: Stem cell engraftment and survival in the ischemic heart. Ann Thorac Surg 92: 1917-1925, 2011.

This work is licensed under a Creative Commons Attribution-NonCommercial-NoDerivatives 4.0 International (CC BY-NC-ND 4.0) License. 